\title{
Adding value to ENCs: Land features
}

\author{
Shachak Pe'eri ${ }^{\text {a, }}$, Noel Dyer ${ }^{\mathrm{a}}$ \\ ${ }^{a}$ Office of Coast Survey, National Oceanic and Atmospheric Administration, Silver Spring, MD, USA (Shachak.peeri@NOAA.gov \\ and Noel.dyer@NOAA.gov) \\ * Corresponding author: Shachak Pe'eri (Shachak.peeri@NOAA.gov)
}

Keywords: Nautical chart, re-scheme, ENC, ECDIS, topographic elevation, transportation routes, roads, raster charts

\begin{abstract}
:
In the 1990's, the International Maritime Organization (IMO) adopted the International Hydrographic Office's (IHO) S57 performance standards for Electronic Navigation Charts (ENC), which enforce standardized content, structure, and format. The IMO also revised its Safety of Life at Sea (SOLAS) chapter V regulations to require Electronic Chart Display and Information Systems (ECDIS) onboard certain SOLAS class vessels, starting from 2018. These systems allow for navigating with ENC data, which has several advantages over paper charts; however, many mariners still prefer traditional paper or raster charts. Through the feedback of key stakeholders such as local pilot associations, it has become apparent that the preference for raster or paper charts is due to the inclusion of non-critical S-57 land features. These S-57 land features, which are typically not added to ENC products, such as roads and elevation contours, can supplement navigational positioning systems by providing visual references, particularly when other landmarks (e.g., spot elevations on major topographic features) are not present on the ENC. Moreover, charting roads on ENC products can be useful for locating water access points. This paper discusses the addition of roads and land elevation contours to NOAA's reschemed ENC suite in an effort to supplement currently charted marine features and land features crossing over water. General cartographic guidelines have also been developed for the representation of these features through ENC scales (i.e., usage bands 3 to 5). Additionally, this paper includes a discussion on the benefits and challenges of incorporating publicly available land transportation data versus traditional sources on ENC products.
\end{abstract}

